\title{
Controversy about coarctation
}

$\mathrm{E}$ ARLIER THIS YEAR WE PUBLISHED A PAPER BY Wong and colleagues with the challenging title "Balloon angioplasty is preferred to surgery for aortic coarctation". ${ }^{1}$ Coarctation is a relatively common congenital malformation and treatment has been available for many years. It would be anticipated that the evidence for the benefits of different approaches to treatment would be relatively clear. However, as the authors pointed out that is not so. They identified there had only been two relatively limited randomised trials comparing surgery and balloon angioplasty. ${ }^{2,3}$ Much of the remaining evidence is difficult to interpret since the studies of angioplasty and surgery are not contemporaneous, or reflect a single institutions preferences for treatment. A further issue is the need for long-term follow-up. Short-term successful relief of coarctation is often possible by either technique, but what of the long-term success in terms of relief of hypertension or complications? ${ }^{4}$ A more recent report of one of the two small, randomised trials attempted to answer these questions. ${ }^{5}$ Essentially this found in a total group of 21 patients, 11 of whom had had balloon angioplasty and 10 surgery, that haemodynamic results were similar. However, aneurysms were detected in $35 \%$ of the angioplasty patients but none of the surgical patients.

Wong and colleagues attempted to analyse the evidence that does exist using a decision tree. This was drawn up from 97 cited articles on results of either balloon angioplasty or surgery for coarctation. Their conclusion was that the evidence showed that balloon angioplasty was the preferred treatment for nonneonatal coarctation. This comprehensive analysis of the evidence is welcome, but there are two important caveats. Firstly, the analysis requires interviews of professionals in which they estimate the outcome for each point in the decision tree. The authors did not include surgeons at this stage. Further, in current practice balloon angioplasty is now often accompanied with the deployment of endovascular stents, but the historical evidence does not reflect this.

In the same issue of the journal we published an editorial comment by Ebels, Maruszewski and
Blackstone titled "What is the preferred therapy for patients with aortic coarctation - The standard gamble and decision analysis versus real results?" 6 Ebels and colleagues found much to criticise in the paper. Firstly, the studies used to inform the decision analysis were largely historical and that generally the surgical papers were older than the angioplasty papers. There were, as we have already noted, only two small randomised trials. They cite data on outcomes from the European Association for Cardiothoracic Surgery, which for a large group of patients showed a contemporaneous mortality of $0.7 \%$, much better than in the studies cited by Wong and colleagues. Secondly, Ebels and colleagues criticise the medical professionals used to estimate outcomes for the decision tree analysis. As we have seen, they did not include surgeons. A further point made is the lack of involvement of parents and families in the decision analysis.

Ebels and colleagues present a strong response to Wong and colleagues' paper and invite a reply: "We anticipate the authors will disagree..and we are more than ready to answer any rebuttal that they wish to mount." Wong and colleagues have risen to the challenge and we are publishing their rebuttal in this issue. We have asked Ebels and colleagues to respond to the rebuttal and their response is also included in this issue.

Bertrand Russell, the eminent twentieth century philosopher, said, "The most savage controversies are those about matters as to which there is no good evidence either way." Avid readers of this column may remember that when we published the original articles by Wong and colleagues and Ebels and colleagues I wrote, "Coarctation is one of the most common congenital abnormalities of the heart and great vessels, and yet we still have not gathered the basic evidence that would allow us to determine the best treatment. Debate is no substitute for evidence. We owe it to our patients to ensure that our recommendations for treatment are based on the best possible evidence." " I will leave you to judge the pros and cons of the debate between our two 
groups of protagonists. I will simply repeat my point, the reason we cannot eventually come to any final view on the best treatment for coarctation is the lack of good contemporary evidence and the relative paucity of evidence about the long-term results of different approaches to treatment. For a common congenital malformation, this is surprising - but it reflects a wider truth - there are relatively few randomized trials of the management of congenital heart malformations. While we have made many advances in the treatment in recent years, there are still many areas of uncertainty and we cannot be sure we are doing the best for our patients without the evidence to back up our treatment strategies. We owe it to them and to ourselves to remedy the situation.

Edward Baker
Editor-in-Chief
E-mail: ctyeditor@cambridge.org

\section{References}

1. Wong D, Benson LN, VanArsdell GS, Karamlou T, McCrindle BW. Balloon angioplasty is preferred to surgery for aortic coarctation. Cardiol Young 2008; 18: 79-88.

2. Shaddy RE, Boucek MM, Sturtevant JE, et al. Comparison of angioplasty and surgery or unoperated coarctation of the aorta. Circulation 1993; 87: 793-799.

3. Hernandez-Gonzalez M, Solorio S, Conde-Carmona I, et al. Intraluminal aortoplasty vs. surgical aortic resection in congenital aortic coarctation. A clinical random study in pediatric patients. Arch Med Res 2003; 34: 305-310.

4. Hager A, Kanz S, Kaemmerer H, et al. Coarctation long-term assessment: significance of arterial hypertension in a cohort of 404 patients up to 27 years after surgical repair of isolated coarctation of the aorta, eve in the absence of restenosis and prosthetic material. J Thorac Cardiovasc Surg 2007; 134: 738-745.

5. Cowley CG, Orsmond GS, Feola P, McQuillan L, Shaddy RE. Long-term randomised comparison of balloon angioplasty and surgery for native coarctation of the aorta in childhood. Circulation 2005; 111: 3453-3456.

6. Ebels T, Maruszewski B, Blackstone EH. What is the preferred therapy for patiens with aortic coarctation - The standard gamble and decision analysis versus real results? Cardiol Young 2008; 18: 18-21.

7. Baker E. From the Editor-in-Chief. Cardiol Young 2008; 18: 1-2. 